Harrison differentiate between somatoform pain disorder and the simple adoption of the sick role by those who are aware that it may be to their advantage to complain?

Finally, a plaintiff's failure to return to work after the settlement of litigation does not necessarily mean that he or she is psychologically sick. It may merely mean that, with the present leve of unemployment and the difference between invalidity benefit and unemployment benefit, the incentive to return to work is low. All that the person has to do is to go on complaining: with the support of a psychiatrist who diagnoses somatoform pain disorder, the prospects for the future are rosy.

London W1N $1 \mathrm{HH}$

LEOPOLD HENRY FIELD

1 Dalal B, Harrison G. Psychiatric consequences of road traffic accidents. BMF 1993;307:1282. (13 November.)

\section{Schistosomiasis in Lake Malawi}

EDrTor,-In the "old days" people used to swim in Lake Malawi with impunity: there were few people about, and if the snails that give rise to schistosomiasis occurred at all their habitat was limited, for the shores are mostly stony and the slopes steep-and the winters are cold. ${ }^{1}$ In the mid1960s the Salima Bay rice scheme was started, and by 1969 there was an epidemic of schistosomiasis among the workers. Concern was expressed abou why the expensive filters did not vouchsafe snail free paddy fields. I was asked to visit the rice scheme and establish what had happened.

The rice fields had attracted people from afar and with them had come the worms and the eggs. The mode of travel of the snails' eggs was obviou as soon as I arrived at the fields: there was an abundance of waterbirds, and the snails' eggs are carried on the feathers of birds. I declared that the filters could not protect the rice scheme from snails' eggs.

Would the filters have protected the lake from the paddy fields? Perhaps. Soon bathing at the grand beach at Salima Bay began to carry the risk of schistosomal infection, and now Salima Bay seems to be the most dangerous area of the great lakes for swimming.

Whenever there was an opportunity on the Malawi side of the lake, irrigation schemes sprang up and dams were built on the escarpments. People increased in number and migrated, and so did the snail and the worm. Geographical pathology is ever changing, not only because of natural forces but because of people.

IMRE J P LOEFLER

\section{Nairobi Hospital}

PO Box 47964,

Kenya

Pugh RNH. Schistosomiasis in Malawi. BMf 1993;307:1354. (20 November.)

\section{Health concerns in Kosovo}

EDITOR,-Everything is possible, according to Lynne Jones's article on the Serbian repression in Kosovo, including a stone age infant mortality of $49 \%$ and a rabbit-like birth rate of $29.5 \%$. Presumably the author, to avoid Serbian propaganda, ignored official data, according to which the infant mortality in Kosovo in 1990 was 34.4 pe $1000^{2}$ - that is, more than 14-fold lower. However, common sense challenges the notion that each inhabitant, including newborn infants and elderly people of both sexes, gives birth to a child virtually once every three years.
No wonder that a land with such extraordinary demographic data should experience a mysterious outbreak that, as "most Albanians believe," "was caused by toxic chemicals being purposely introduced into the ventilation vents of schools, making over 3500 children ill. (Serbian and Albanian children had classes in separate shifts.)"' The implication is that in the Podujevo school, where the epidemic originated, ${ }^{3}$ all 80 Serbs attended classes in one shift and the 1984 Albanians attended the opposite one. As the nationality ratio is similar all over Kosovo, the likelihood of a few Serbian children having a shift in any school exclusive to themselves is low. Moreover, there is a little likelihood of a child (of any nationality) in Kosovo ever having seen any ventilation system more sophisticated than a window.

Space does not permit me to challenge in detail the statement on "signs of physical intoxication" shown by some of the patients as proof of poisoning. But a commission headed by a Slovenian and appointed by another Slovenian (who was in charge of health care in the then federal Yugoslavia) described the condition as "induced psychogenic reaction of a hysteriform type with superposition." ${ }_{3}$ This finding accords with the bizarre symptoms found in 35 patients, whose families trusted only Slovenian doctors and took the patients to Ljubljana. In an official report the main manifestations were listed as uncontrolled screaming, waving arms, and convulsions, along with forced closure of the eyes and frowns.

It is true that "refusal of Albanian teachers to teach the new unified Serbian school curriculum has resulted in their dismissal." Unfortunately, nobody explained to Jones that it was not the content of the curriculum but the procedure that mattered: by accepting any curriculum the teachers would recognise Kosovo as a part of Serbia rather than a self proclaimed republic. An analogy may help: if Wales decided to secede, Welsh teachers (or clerks, doctors, etc) would be wrong to expect salaries from the government they otherwise ignored.

\section{Department of Community Medicine,}

ZORAN RADOVANOVIC

Faculty of Medicine,

Kuwait University,

Kuwait

1 Jones L. Coping with Serbian repression in an Albanian population. $B M 7$ 1993;307:112-4. (10 July.)

Federal Institute of Statistics. Statistical yearbook '91 on public health and health care in Yugoslavia. Beograd: FIS, 1992.

3 Federal Commission of Experts. Report of mass outbreak of health disorders in Kosovo. Beograd: Federal Ministry of Labour, Health, Veteran Administration and Social Politics, 1990

4 Krejci F, Jamsek M. Report on Kosovo patients examined in the University Clinical Centre, Ljubljana from 26 to 31.03.1990. University Clinical Centre, Ljubljana from

\section{Overestimation of cost savings in prevention of osteoporosis}

EDITOR,-In their assessment of the economic impact of a scheme for early discharge of patients with hip fracture William Hollingworth and colleagues used the marginal cost method and concluded that use of the readily available cost per day produces an overestimate of $41 \%(((189 \times 41 \cdot 7)-$ $5606) / 5606)$ for patients with no access to the early discharge scheme and $34 \%(((189 \times 32.5)-4591) /$ 4591) for patients with access to the scheme. ${ }^{1}$ A similar approach to costing was used in a study conducted recently in Aberdeen and the same conclusion was reached even though the average length of stay is considerably shorter in Aberdeen than in Peterborough: 29.6 days compared with 41.7 days. The overestimation of costs in Aberdeen would be $23 \%$ for acute care and $48 \%$ for rehabilitation if the specialty costs per day were used.

We deduce, therefore, that those cost effective- ness studies of hormone replacement therapy to prevent osteoporosis in Britain that have used the cost per day will have overestimated the likely financial benefits to the NHS. ${ }^{23}$

FIONA FRENCH DAVID TORGERSON RICHARD W PORTER

University of Aberdeen

Aberdeen AB9 2ZD

1 Hollingworth W, Todd C, Parker M, Roberts JA, Williams R Cost analysis of early discharge after hip fracture. $B M Y$ 1993;307:903-6 (9 October)

2 Daly E, Roche M, Barlow D, Gray A, McPherson K, Vessey M HRT: an analysis of benefits, risks and costs. $\mathrm{Br}$ Med Bull 1992;48:368-400.

3 Goddard $M$. The cost-effectiveness of hormone replacemen therapy: a review. York: Centre for Health Economics, 1990 (Discussion paper 73.)

\section{Resource implications of cancelled operations}

EDrTor,-Cancellation of a planned elective operation is sometimes unavoidable because of unpredictable variations in emergency workload, but cancellations due to the distribution of resources can be identified by audit and may be preventable within existing budgets. Repeated admissions for operations that are later cancelled give rise to duplication of essential investigations and further wastage of resources.

A prospective audit of cancellations of major aortic surgical procedures during 1992 was conducted in the vascular unit at the John Radcliffe Hospital in Oxford. The key resource that was unavailable and responsible for each cancellation was identified and the cost implications evaluated Over the year, 35 elective aortic procedures were performed. The ratio of male to female patients was $10: 1$, and the mean age of the patients was 66.6 (SD 10.9) years. Twenty of the patients had their operations cancelled at least once (mean $1.8(1.4)$ times), accounting for 36 cancellations; in one case the operation was cancelled seven times. On each occasion the operation was cancelled because no bed was available in the intensive therapy unit.

The resource implications of these cancelled operations can be measured as a loss of surgical workload and resources wasted. Over the seven years 1985-91 an average of 43 elective aortic procedures were performed each year. In 1992 only 35 procedures were performed (that is, a 19\% decrease in workload). Resources wasted by the 36 cancellations included extra bed days in the surgical wards, operating time in theatre not used because of late cancellations, unused cross matched blood, and repeated ancillary tests (table). Current costings for the vascular unit indicate that these wasted resources, at a conservative estimate, amounted to $£ 33000$ over the year.

Delivery of services requires perfect matching between key resources. Specific deficiencies in resources responsible for cancelled operations will vary among hospitals and in the same hospital over time. In 1992 the elective aortic operations in

Resources wasted when 36 major aortic procedures were cancelled

\begin{tabular}{lr} 
& No \\
\hline Ward bed days & 78 \\
Theatre time & 65 \\
Cross matched blood (units) & 138 \\
Ancillary tests: & 26 \\
Full blood count & 26 \\
Creatinine and electrolytes & 31 \\
International normalised ratio & 2 \\
Liver function tests & 11 \\
Kaolin cephalin clotting time & 10 \\
Blood glucose & 7 \\
Electrocardiography & 5 \\
Chest radiography &
\end{tabular}


Oxford were cancelled because beds were not available in the intensive therapy unit. Identifying the problem has allowed a solution to be devised, and we look forward to fewer cancellations of major elective operations in the future.

D L MCWHINNIE J A MICHAELS J COLLIN PJMORRIS

Nuffield Department of Surgery, University of Oxford, John Radcliffe Hospital Oxford OX3 9DU

\section{Women consultants}

EdrToR,-Luisa Dillner castigates the East Anglian region for a poor record in appointing women consultants. ${ }^{1}$ In the two years to September 1993, 47 consultant vacancies were filled in the region. Women were more likely to be shortlisted and more likely to be appointed than men (table). A

Number of male and female applicants for consultant posts in East Anglian region

\begin{tabular}{lccc}
\hline & $\begin{array}{c}\text { No of } \\
\text { applicants }\end{array}$ & $\begin{array}{c}\text { No (\%) } \\
\text { shortlisted }\end{array}$ & $\begin{array}{c}\text { No (\%) } \\
\text { appointed }\end{array}$ \\
\hline $\begin{array}{l}\text { Female } \\
\text { Male }\end{array}$ & 37 & $25(68)$ & $12(32)$ \\
& 242 & $118(49)$ & $35(14)$
\end{tabular}

woman was apGointed to 12 of the 22 posts for which there was at least one female applicant. Hence when women apply they stand at least as good a chance of being appointed as men. We suspect that the number of female applicants is small not because of "prejudice and discrimination against women" but because of the difficulties a partner (who is often also in a profession, if not a doctor) would have in finding suitable employment in the small towns in which most East Anglian hospitals are found.

JOHN STARK HEATHER DEMERY

\section{East Anglian Postgraduate Medical and \\ Dental Education Committee, \\ Addenbrooke's Hospital, \\ Cambridge CB2 2SP \\ 1 Dillner $\mathrm{L}$. Why are there not more women consultants? $B M F$ 1993;307:949-50. (16 October.) \\ Information management and patient privacy}

EDrToR,-Alison Tonks's editorial was a useful summary of some of the key parts of the NHS Management Executive's information management and technology strategy and will assist in further disseminating the objectives of the strategy to the medical profession.' Ensuring that the clinical professions are aware and involved is important, and we are making considerable efforts to achieve this. Indeed, we would be pleased to take any opportunity to present the strategy to clinical audiences.

Parts of the article did, however, give only a partial and somewhat misleading view of the work which is being directed to protecting personal data. We would like to redress the balance.

It was implied that the NHS population registers of administrative details of patients that are being developed would be a totally new feature of the NHS; would be vulnerable to unauthorised access; and would be used for non-NHS purposes. All family health services authorities already have comprehensive patient registers, as do many other parts of the NHS. The NHS Central Register holds basic details and the NHS number of all individuals in England as from birth. Access to these registers is controlled, and over many years there have been few, if any, major problems of unauthorised access. The new registers will build on these but will additionally be designed for joint ownership by several NHS organisations and, in that respect, will specifically have additional built in access controls and audit trails.

The article additionally picks up a theme that has been evident elsewhere: that the new NHS number may become a national identity number. Again, it needs to be recognised that everybody already has a NHS number and that has been the case for over 50 years. The intention is simply to replace the existing 23 formats for the existing number with one that is less susceptible to transcription error and can be checked in computers by a check digit.

Because the NHS has handled population registers and NHS numbers for many years withou major confidentiality breaches, and without the number being used outside the NHS, no need has been foreseen to take special additional legislative measures to protect new versions. The NHS number is protected by Crown copyright, and the new forms of population register will have technical access controls and administrative controls. The management executive is determined to ensure that the NHS number and population registers are, as now, used only for NHS purposes, and the data protection registrar has been informed that if the existing and new controls prove to be inadequate, legislation will then-but only thenbe considered.

Finally, Tonks raised the question of protecting confidentiality in an environment of increased electronic networking. The management executive is very conscious of this need. The use of electronic networks to transmit data is growing daily in the NHS and is currently not coordinated nationally. That is why the management executive has decided that networking (for data, voice, images, and radio frequency mobiles) will be subject to a national strategy within which national standards will be implemented. These standards must include security measures. Outline proposals for appropriate measures have been formulated and are considerably more comprehensive than any currently being applied. The measures are to be developed in close collaboration with the clinical professions, and we are currently seeking a range of professional representatives including the Joint Consultants Committee and General Medical Services Committee to join a working group for that purpose.

The management executive has always regarded the protection of the confidentiality of personal data as a serious matter and, in collaboration with all parties, we intend to see that the NHS continues to do so.

G P A WINYARD R T ROGERS

NHS Management Executive Leeds LS2 7UE

1 Tonks A. Information management and patient privacy in the NHS. BMf 1993;307:1227-8. (13 November.)

\section{No deception in symposium supplement}

EDITOR,-Peter Lurie and colleagues express concern $^{1}$ that the International Committee for the Evaluation of Hypertriglyceridemia as a Vascular Risk Factor inadequately identified support it received from Parke-Davis for a symposium issue of the American fournal of Cardiology that its members authored and edited. ${ }^{2}$ They also question the objectivity of the supplement. We, the cochairmen of the committee, wish to correct their misapprehensions.
The international committee, comprising 28 eminent researchers, was established and sponsored by the Fondazione Giovanni Lorenzini of Milan and the Giovanni Lorenzini Medical Foundation of Houston. Both are non-profit, independent foundations devoted to international research and education in medicine, biochemistry, and pharmacology. Their activities are supported by a variety of public and private sources. The committee's task was to review comprehensively the data on plasma triglyceride concentrations in relation to the risk of cardiovascular disease and from that review to provide a written perspective, including recommendations on managing hypertriglyceridaemia.

There was no attempt at deception in the supplement: the American fournal of Cardiology does not peer review supplements; it publishes them under separate cover and clearly denotes the nature of their contents. It is standard practice for supplements to be reviewed by only their designated editors, but in this instance an additional peer reviewer, or reviewers, was assigned to each article. Soliciting underwriters for journal supplements is standard practice as well: publication was underwritten by the Giovanni Lorenzini Medical Foundation. Parke-Davis partly supported the dissemination of the printed journal but did not become involved until after the committee's deliberations had ended and the document had been written. Neither Parke-Davis nor any other company was involved in the writing or approval of the supplement.

As evidence of the committee's bias Lurie and colleagues state that the published supplement's "concluding article, on the pharmacological management of patients with hypertriglyceridaemia, devotes nearly half its space to gemfibrozil (Lopid, Parke-Davis) and other fibrates." There are only two major categories of approved lipid lowering agents with appreciable clinical triglyceride lowering activity: nicotinic acid and the fibrates. Statins produce only modest reductions in triglyceride concentrations. The two and a half page article in question, one of 11 subject specific supporting articles in the 42 page supplement, includes one column on nicotinic acid and one and two third columns on bezafibrate, fenofibrate, and gemfibrozil. ${ }^{3}$ The section on fibrates is longer because the different agents vary in the characteristics reviewed (for example, pharmacokinetics, dosage). No trade names are given. The supplement's introduction, which presents the committee's conclusions, states in bold face that drug treatment to lower triglyceride concentrations "may be considered if diet is ineffective, although this remains controversial." 4

Lurie and colleagues also state that the article failed to mention "the increased non-cardiovascular mortality after treatment with gemfibrozil." The international committee's deliberations preceded the debate about whether ancillary data and 3.5 year follow up data from the Helsinki trial indicated excess mortality. These results were not available, and the Physicians' Desk Reference of 1990 cited by Lurie and colleagues contains only 1.5 year follow up data, at which point there was no significant excess mortality.

ANTONIO M GOTTO

GERD ASSMANN

Department of Medicine

Baylor College of Medicine,

Methodist Hospital

Houston, Texas 77030, USA

1 Lurie P, Newman TB, Hulley SB. Caution over journal supplements. $B M f$ 1993;307:1140. (30 October.)

2 International Committee for the Evaluation of Hypertriglyceridemia as a Vascular Risk Factor. The hypertriglyceridemias: demia as a Vascular Risk Factor. The hypertriglycer
risk and management. Am f Cardiol 1991;68(suppl).

3 Franceschini G, Carlson LA. Management of hypoertriglyceridemic patients. D. Pharmacologic management of hypertrigly-
danceschini G, Carlson LA. Management of hypoertriglyceridemic patients. D. Pharmacologic management of hype
ceridemic patients. Am $\mathcal{G}$ Cardiol 1991;68(suppl):40-2A.

4 Assman G, Gotto AM Jr, Paoletti R. Introduction. Am f Cardiol 1991;68(suppl):1-4A. 